\title{
Prototipe Mesin CNC 2D Berbasis Arduino Uno
}

\author{
Ernes Cahyo Nugroho*1, Agung Nugroho ${ }^{2}$, Isti Hendriyanto ${ }^{3}$ \\ ${ }^{1,3}$ Program Studi Sistem Komputer, STMIK AUB, Surakarta, Indonesia \\ ${ }^{2}$ Program Studi Sistem Informasi, STMIK AUB, Surakarta, Indonesia \\ e-mail: *1ernes.cahyo@stmik-aub.ac.id, 2agung_new@stmik-aub.ac.id, \\ ${ }^{3}$ hendrishinigami17@gmail.com
}

\begin{abstract}
Abstrak
Papercut is a craft cut on paper media with the initial stage of making the design is done still manually. It is in less effective and efficient value. By utilizing the CNC machine workmanship will be more quickly resolved, but the price in the market this machine is still relatively expensive for small size. To meet the needs of papercut craftsmen then need to make a CNC machine that is specially for papercut manufacture of course with a much more affordable price. The main purpose of this research is to design and make Prototype of CNC Machine Based Arduino Uno for the purpose of making design or pattern of papercut craft which can work automatically, both for mass production and production of job order. Especially products that have intricate designs and require precise precision. The research method used in this thesis is descriptive method. Overall the tool is divided into circuit blocks, including: inputs, process units, and outputs. The input consists of Shield L293D as the command giver to the part of the process unit to be processed by the process unit ie Arduino Uno R3. The output block is Motor Stepper X, Y and Motor Servo Z to execute the program command given. With this machine is expected to provide solutions for Papercut craftsmen so that the design stage I pattern is not done manually. The result of this research is Prototype of Arduino Uno CNC Machine that can create and print pattern or drawing design automatically in complete with motor rotation speed setting. It can be concluded that the machine is designed using two stepper motors as a drive on the $X$ axis and $Y$ axis, and a DC motor is parallel to the $X, Y$ position used for printing. The step position of the motor will be represented in the $2 D$ coordinate model on a millimeter scale. The data entered is then sent via serial communication to the microcontroller as the control center of the machine.
\end{abstract}

Kata kunci: CNC Machine, Papercut, Arduino R3

\section{PENDAHULUAN}

Kehidupan masyarakat modern saat ini istilah papercut di gunakan untuk berbagai keperluan kesenian seperti hiasan dinding, dekorasi rumah, kado hadiah, ucapan selamat, upacara pernikahan, sampai upacara penguburan. Bentuknya pun sangat bervariasi, mulai dari karakter - karakter huruf maupun bentuk-bentuk hewan, tumbuhan, dan manusia. Papercut merupakan seni memotong pada media kertas, hingga menghasilkan sebuah bentuk atau pola yang diinginkan. Dalam pembuatannya tahap awal yang perlu di perhatikan adalah gambar / desain pola secara manual yang kemudian di potong.

Teknologi mesin untuk pembuatan papercut yang beredar di pasaran Indonesia saat ini adalah mesin perkakas CNC yang harganya masih relatif mahal untuk ukuran kecil kisaran 30 40 juta. Hal tersebut tentunya akan menjadi permasalahan tersendiri bagi seseorang yang akan memulai usaha pembuatan kerajinan papercut dengan modal awal yang di perlukan begitu

Received May 6, 2019; Revised May 27, 2019; Accepted June 12, 2019 
besar. Oleh karena hal tersebut maka perlu penyesuaian kebutuhan mesin CNC yang di khususkan untuk pembuatan papercut dengan harga yang lebih terjangkau / low cost.

Mesin CNC (Computer Numerically Controlled) merupakan mesin yang dikontrol oleh komputer dengan menggunakan bahasa numerik (data perintah dengan kode angka, huruf dan simbol) sesuai standar ISO. Sistem kerja teknologi CNC lebih sinkron antara komputer dan mekanik bila dibandingkan dengan mesin perkakas yang sejenisnya, maka mesin perkakas CNC lebih teliti, lebih tepat, lebih fleksibel dan cocok untuk produksi massal.

Dengan adanya permasalahan - permasalahan tersebut, penulis membuat "PROTOTIPE MESIN CNC 2D BERBASIS ARDUINO UNO" dengan Software GBRL Controller yang terjangkau atau low cost dibandingkan Mesin CNC konvensional yang secara khusus di gunakan untuk pembuatan desain suatu pola/gambar pada kertas sebagai keperluan dalam kerajinan papercut dan menggunakan end effector berupa pena, Tujuan di buatnya alat ini agar dapat membantu memecahkan permasalahan masyarakat yang akan memulai usaha kerajinan papercut.

Hasil dari penelitian ini adalah Prototipe Mesin CNC berbasis Arduino Uno yang dapat membuat dan mencetak desain pola atau gambar secara otomatis di lengkapi dengan pengaturan kecepatan putaran motor. Kesimpulan alat ini secara keseluruhan yaitu menggunakan motor servo sebagai pengatur koordinat dari End Effector. Sistem koordinat yang digunakan dalam perancangan prototipe mesin $\mathrm{CNC}$ adalah Koordinat Kartesian atau Rectangular Coordinated. Diperlukan 2 (dua) buah motor stepper bipolar dalam membuat prototipe mesin CNC. Sesuai dengan standar koordinat kartesian yakni koordinat X, koordinat Y dan koordinat Z. L293D module digunakan sebagai driver motor stepper CNC. Software Processing untuk mengirimkan kode G-Code ke Arduino UNO melalui komunikasi serial. Arduino sebagai pengeksekusi program yang dikirimkan dari Software Processing.

\section{METODE PENELITIAN}

\subsection{Diagram Blok}

Untuk memahami dari proses rancangan dalam penelitian ini, penulis membuat gambar blok diagram rangkaian seperti gambar 1 dibawah ini:

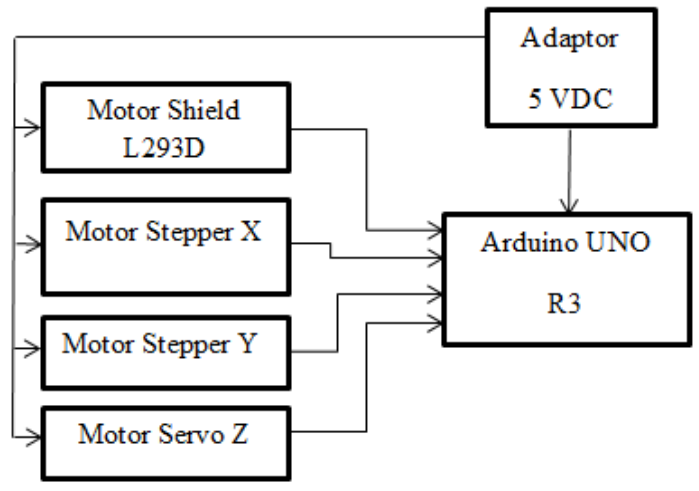

Gambar 1 Diagram Blok

Rangkaian blok input Adaptor mensuplaikan ke arduino tegangan sebesar 5 volt kemudian arduino membagi tegangan tersebut ke motor Shield L293D, motor stepper, dan motor servo masing-masing 5 volt.

GO INFOTECH: JURNAL ILMIAH STMIK AUB Vol. 25, No. 1, Juni 2019 : 43 - 52 


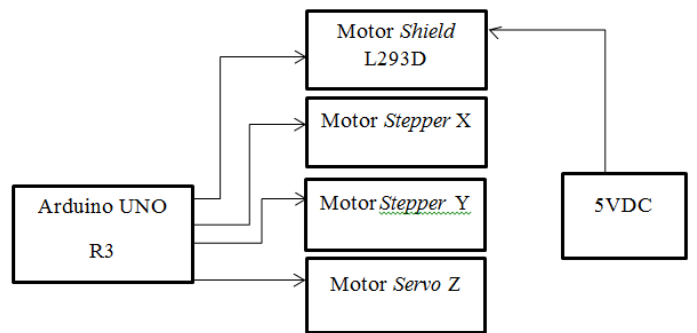

Gambar.2 Diagram Blok Output

Berdasarkan gambar 1 dan 2 maka dapat diuraikan fungsi dari masing-masing blok yaitu:

a. Arduino Uno R3

Arduino sebagai otak dari sistem, data input dari pengguna dan motor diproses oleh mikrokontroler yang hasilnya outputnya akan diumpankan ke Motor Shield L293D, Motor Stepper dan Motor Servo.

b. Motor Shield L293D

Motor Shield L293D dalam rangkaian ini yang akan berfungsi sebagai driver motor untuk memerintahkan motor bergerak.

c. Motor Stepper $\mathrm{X}$

Posisi motor bergerak mengarah ke kiri ke kanan dengan koordinat awal 0,0(horizontal).

d. Motor Stepper Y

Posisi motor bergerak mengarah maju mundur dengan koordinat awal 0,0 (vertikal).

e. Motor Servo Z

Berfungsi sebagai pengatur naik turunnya pena.

2.2. Rangkaian Motor Shield L293D

Motor Shield L293D digunakan sebagai driver motor stepper dan motor servo untuk mengatur pergerakan motor. Konfigurasi pin dapat dilihat pada gambar 3 berikut.

\subsection{Motor Servo $X$}

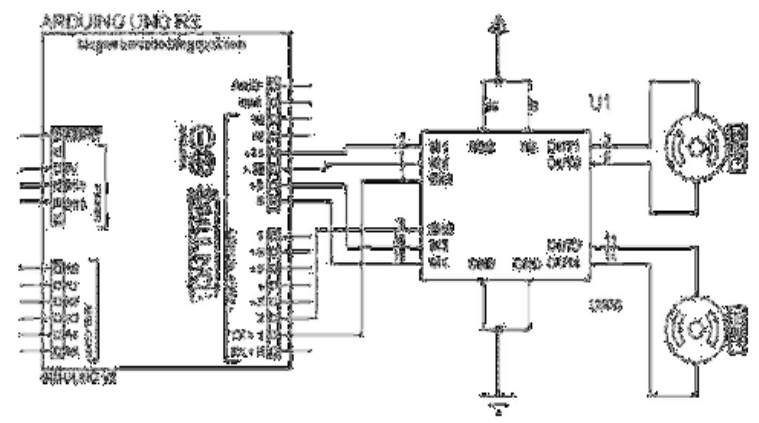

Gambar 3 Rangkaian L293D

Motor Servo Standar $180^{\circ}$ Motor servo jenis ini hanya mampu bergerak dua arah (CW dan $\mathrm{CCW}$ ) dengan defleksi masing-masing sudut mencapai $90^{\circ}$ sehingga total defleksi sudut dari kanan - tengah - kiri adalah $180^{\circ}$. Rangkaian motor servo dapat dilihat pada gambar 4 sebagai berikut : 


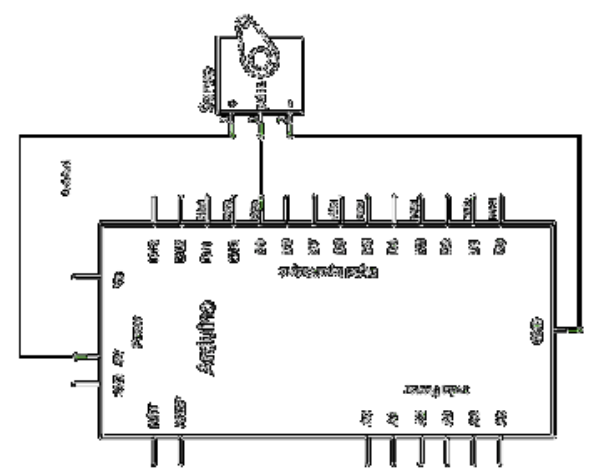

2.4. Adaptor $5 \mathrm{~V} 2 \mathrm{~A}$

Gambar 4 Rangkaian Motor servo

Inputan tegangan listrik sebesar 5VDC dan output 2 ampere. Bentuk fisik adaptor dapat dilihat pada gambar 5 sebagai berikut :

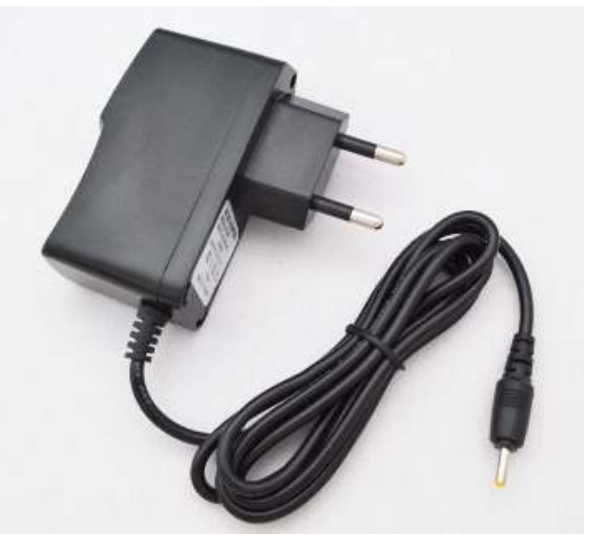

Gambar 5 Adaptor 5V 2A

2.5. Rancangan Perakitan Komponen Secara Keseluruhan

Perakitan keseluruhan dari semua komponen dapat dilihat pada gambar 6 sebagai berikut :

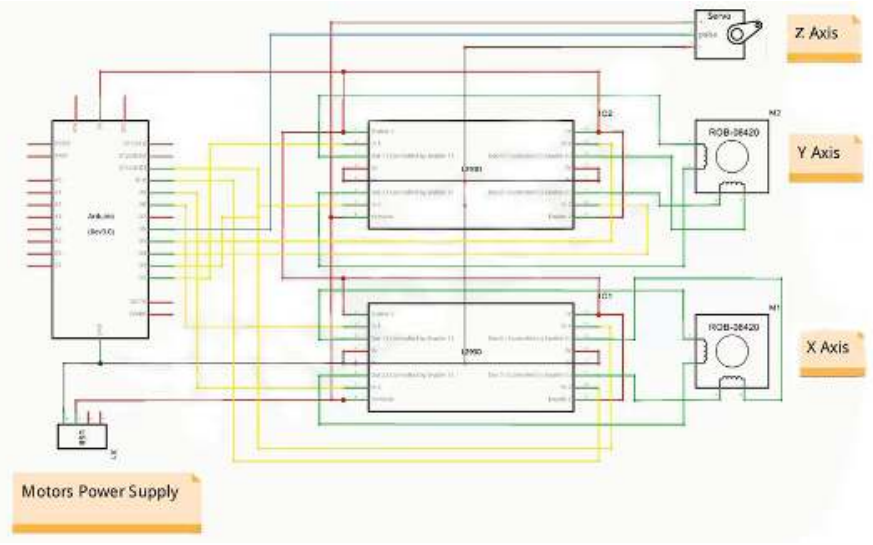

Gambar 6 Rancangan Perakitan Komponen Keseluruhan

3. HASIL DAN PEMBAHASAN

\subsection{Cara Kerja Alat}

GO INFOTECH: JURNAL ILMIAH STMIK AUB Vol. 25, No. 1, Juni 2019: 43 - 52 
Alat memerlukan tegangan Listrik 5 Volt DC selanjutnya 5 volt DC akan dibagi oleh Arduino. Menghubungkan kabel arduino dengan pc, Setelah posisi koodinat telah berada pada titik $(0,0)$ mesin akan menunggu hingga ada masukan data berupa posisi koordinat. Data yang diterima kemudian akan diproses sesuai dengan bit yang diterima. Dalam proses pengiriman, data dikirim dalam 12 bit dimana pada bit 1 yaitu sebagai penanda awal dimulainya pengiriman data, Bit 2 yaitu kode untuk proses yang akan dilakukan Bit $3-7$ untuk nilai koordiant $\mathrm{x}$, bit 8 11 untuk nilai koordinat $y$, dan bit 12 untuk penanda akhir pengiriman data. Pada bit ke 2 pada pengiriman terbagi atas perintah penggambaran, perintah koordinat dan perintah untuk melakukan restart mesin.

\subsection{Perakitan Alat}

Didalam proses perakitan alat dimulai dengan merangkai tanpa menyoldir komponen elektronika yang telah disiapkan karena komponen menggunakan modul yang sudah jadi rangkaian elektronik seperti halnya Arduino Uno R3, Shield L293D, dan komponen lainnya yang dilakukan dengan langkah satu persatu dengan teliti dan hati-hati sesuai dengan gambar skema rangkaian.

Peralatan yang dibutuhkan pada saat perakitan adalah Multimeter yang merupakan alat pengukur yang digunakan untuk mengukur tegangan, arus dan hambatan listrik. Multimeter merupakan alat untuk mengecek setiap komponen apakah masih dalam keadaan baik atau sudah rusak pada saat sebelum dilakukan penyoldiran.

\subsection{Perakitan Rangkaian}

a. Arduino

Arduino ini tidak melakukan proses penyolderan dan perakitan karena dalam rangkaian ini berupa modul dalam kemasan sehingga rangkaian tinggal menghubungkan ke catu daya dan input dan output ke motor dan elektronika output lain. Rangkaian arduino dapat dilihat pada gambar 7 sebagai berikut :

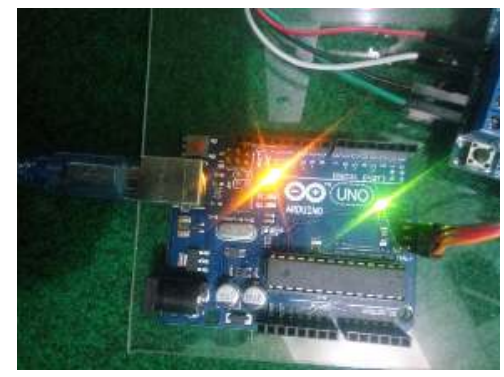

b. Shield L293D

Gambar 7 Rangkaian Arduino setelah perakitan

Penggabungan komponen Shield L293D dengan arduino R3 dilakukan secara hati-hati dengan membaca skema rangkaian yang telah dibuat sebelumnya. Di bawah ini gambar 8 rangkaian setelah proses perakitan komponen:

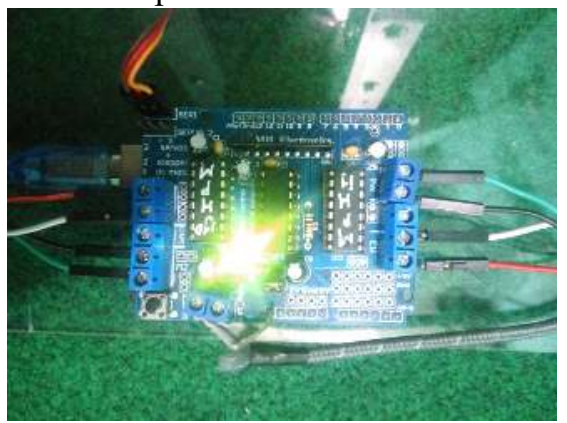

c. Motor Stepper X

Gambar 8 Rangkaian Shield L293D setelah perakitan 
Pemasangan motor stepper sumbu X pada casing dan menghubungkannya Shield L293D dilakukan secara hati-hati dengan membaca skema rangkaian yang telah dibuat sebelumnya. Di bawah ini gambar 9 rangkaian setelah proses perakitan komponen.

d. Motor Stepper Y

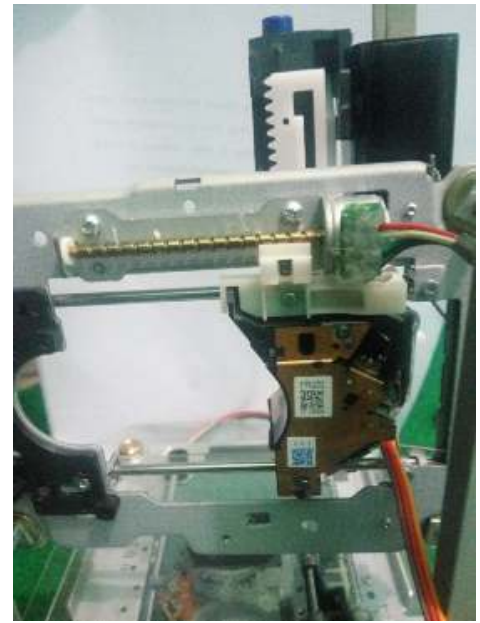

Gambar 9 Rangkain motor stepper X

Pemasangan motor stepper sumbu Y pada casing dan menghunbungkannya Shield L293D dilakukan secara hati-hati dengan membaca skema rangkaian yang telah dibuat sebelumnya. Di bawah ini gambar rangkaian setelah proses perakitan komponen. Rangkaian motor stepper sumbu Y dapat dilihat pada gambar 10 sebagai berikut :

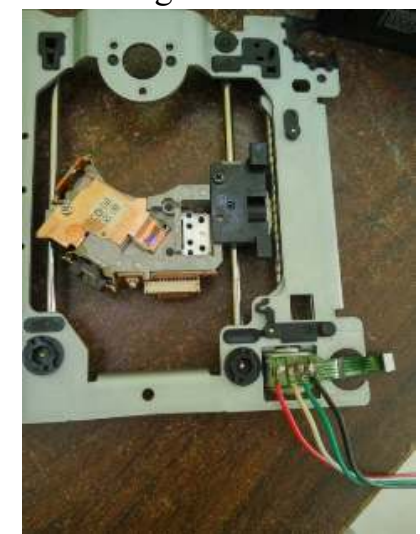

e. Motor Servo Z

Gambar 10 Rangkaian Motor Stepper Y

Pemasangan motor servo sumbu $Z$ pada casing dan menghunbungkannya Shield L293D dilakukan secara hati-hati dengan membaca skema rangkaian yang telah dibuat sebelumnya. Di bawah ini gambar 11 rangkaian setelah proses perakitan komponen. 


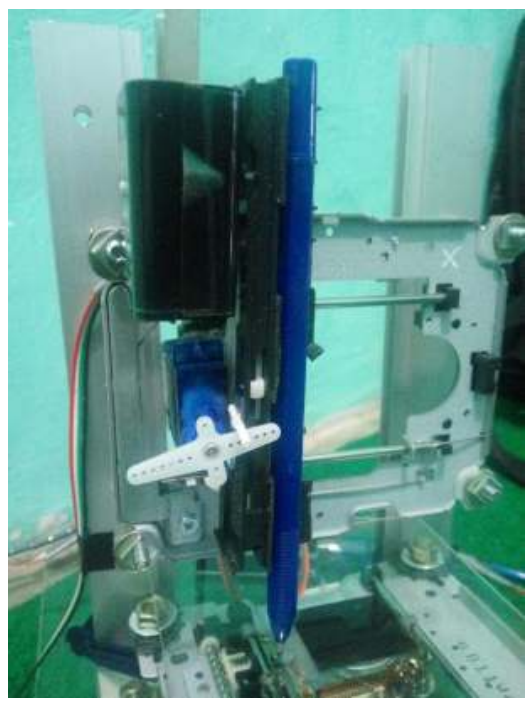

\subsection{Pengujian Tegangan Setiap Blok}

Gambar 11 Rangkaian Motor Stepper Z

Setelah perakitan alat telah sesuai dengan skema rangkaian, maka langkah selanjutnya adalah pengujian tegangan setiap blok rangkaian. Pengujian ini dimaksudkan untuk menguji kinerja tiap blok bagian alat secara keseluruhan. Pengujian dilakukan dengan memberikan tegangan masukan pada rangkaian yang diuji, menganalisis tegangan keluaran, tinjauan rancangan dan perbaikan kinerja.

Apabila tegangan keluaran telah sesuai maka pengujian tiap blok dihentikan dan pada bagian blok tersebut dinyatakan telah berfungsi dengan baik dan dilanjutkan pada pengujian blok berikutnya. Namun apabila tegangan keluaran belum mencapai kondisi yang dikehendaki, maka dilakukan perbaikan dengan mengganti nilai komponen-komponen yang lain .

a. Pengujian Arduino

Pengujian terhadap Arduino digunakan untuk mengetahui tegangan keluaran Arduino saat keadaan logika 0 maupun logika 1. Berikut ini adalah gambar 12 rangkaian Arduino .

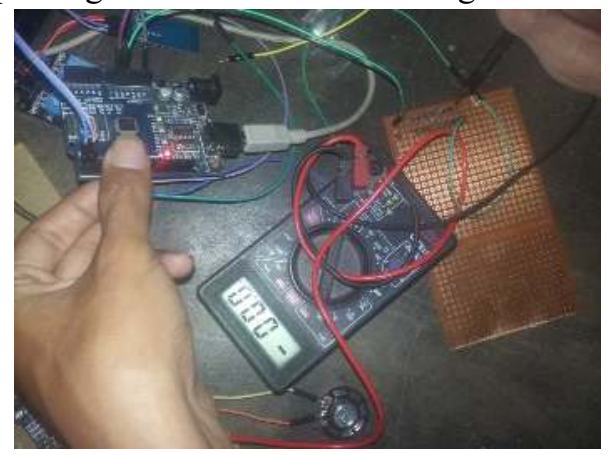

Gambar 12 Hasil pengukuran Arduino logika 0

Hasil pengukuran logika 1 dapat dilihat pada gambar 13 sebagai berikut :

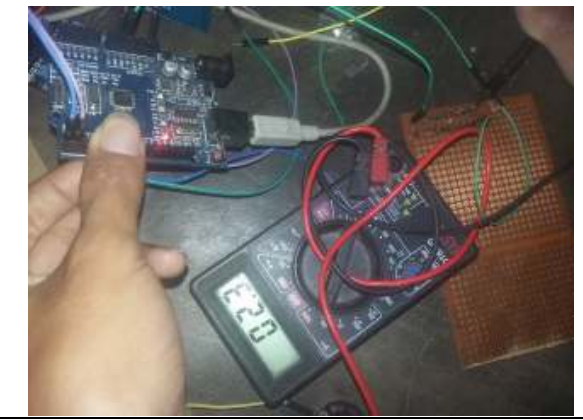

Prototipe Mesin CNC 2D Berbasis Arduino Uno (Ernes) 
Gambar 13 Hasil Pengukuran Arduino Logika 1

Dari hasil pengukuran yang dilakukan ternyata didapatkan hasil bahwa dalam keadaan logika 0 tegangan keluaran dari Arduino adalah sebesar $0.03 \mathrm{~V}$ serta untuk logika 1 didapatkan data pengukuran sebesar 4,94 V. Data ini dinilai cukup relevan dan sesuai dengan data sheet dari Arduino.

b. Pengujian Shield L293D

Pengujian Shield L293D bertujuan untuk mengetahui apakah rangkaian dapat berfungsi dengan baik sehingga tidak terjadi hambatan dalam hal pengujian rangkaian lainnya. Pengujian shield L293D dilakukan dengan cara multimeter diseting ke menu voltase terlebih dahulu kemudian meletakkan probe multimeter EXT_PWR, kemudian letakkan pin + dan - . Dan hasil dari pengujian saat shield L293D hidup tegangan keluar 4.9 volt dan saat shield L293D mati tegangan 0,0 volt.

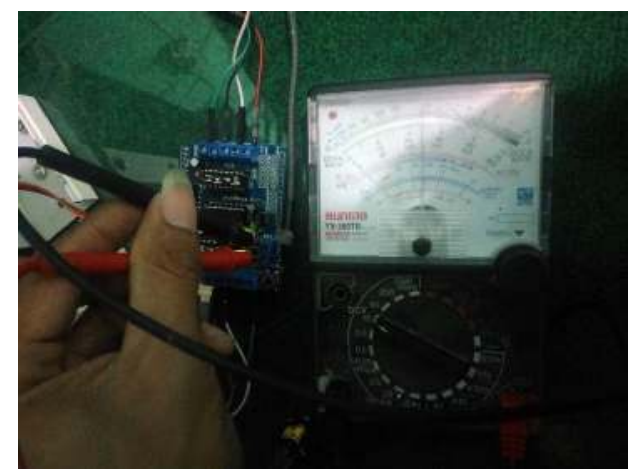

Gambar 14 Hasil Pengujian L293D Saat Hidup

c. Pengujian Motor Stepper

Pengujian motor stepper dilakukan dengan pengujian tegangan keluaran, komponen utama meliputi driver Shield L293D dan adapun peralatan tambahan dalam mendukung proses pengujian yaitu multimeter.

Motor Stepper di uji dengan cara memberikan catu 5 VDC dan menguji gerakan motor, sedangkan tegangan keluaran langsung diamati dengan multimeter. Dari pengujian didapatkan data sebagai berikut.

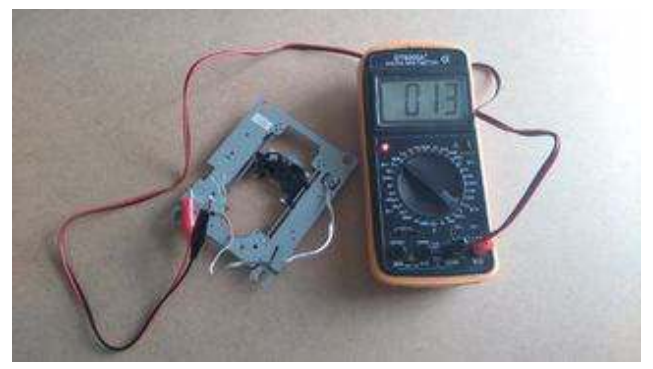

\section{d. Pengujian Motor Penggerak}

Gambar 15 Pengujian Tegangan Motor Stepper

Motor penggerak pada mesin terdiri dari dua motor stepper, yaitu motor stepper sumbu x, dan motor stepper sumbu y, dimana tiap motor mempunyai drivernya sendiri-sendiri yang terhubung ke mikrokontroler. Pengujian dilakukan dengan cara memberikan sinyal-sinyal diskrit 4 bit secara berkesinambungan melalui barisan perintah pada mikrokontroler. Pengontrolan yang dilakukan menggunakan metode kontrol half step dengan 8 siklus perlangkah. Sinyal kemudian diteruskan ke driver yang nantinya mengontrol motor penggerak. Hasil pengujian motor penggerak dapat di lihat pada tabel 1 sebagai berikut :

Tabel 1. Hasil Pengujian Motor Penggerak 


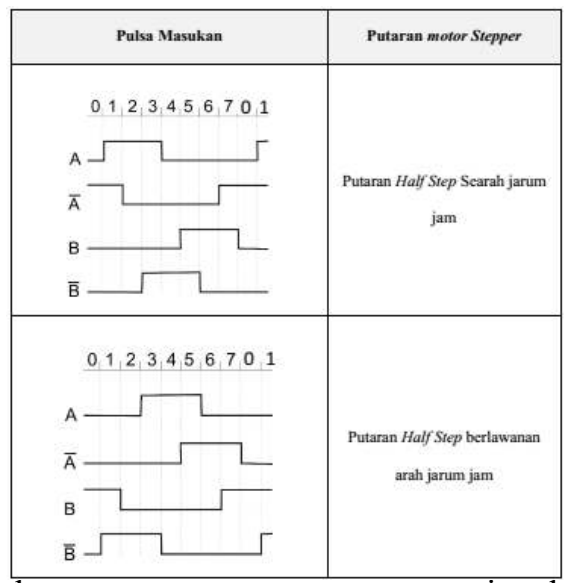

Dari pengujian diperolah bahwa motor stepper merespon sinyal keluarandari driver dengan baik, motor stepper dapat bergerak searah maupun berlawanan arah jarum jam.

e. Pengujian Kecepatan Motor Stepper

Pengujian menggunakan aplikasi stopwatch yang berada di smartphone. Pengujian ini bertujuan untuk mengetahui durasi waktu lama pencetakan gambar sesuai dengan ketetapan kecepatan yang telah di tentukan.

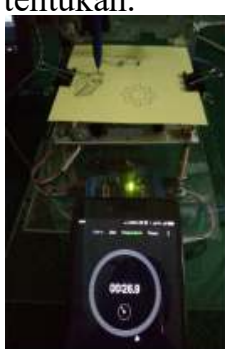

1. set speed 0,100 inch

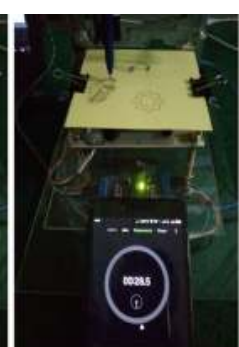

2. set speed 0,010 inch

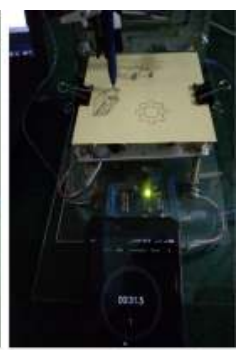

3. set speed 0,001 inch

Gambar 16 Pengujian Kecepatan Motor Stepper

Dari pengujian diperolah bahwa kecepatan motor stepper sesuai dengan set speed yang telah di tentukan dengan perbedaan durasi yang di dapatkan.

f. Pengujian Motor Servo

Pengujian dilakukan dengan menghubungkan VCC servo pada tegangan $5 \mathrm{~V}$ dan $0 \mathrm{~V}$ (Grond) untuk kabel ground, kemudian memberikan pulsa PWM dengan lebar 20ms pada pin input servo. Untuk mengatur putaran servo diberikan signal high atau Ton selama $1 \mathrm{~ms}-2 \mathrm{~ms}$ untuk setiap 20ms pulsa PWM. Dan Pengujian motor pena dilakukan dengan memberikan sinyal high atau low dari PORT D2. Berikut hasil pengujian motor servo yang dilakukan. Dari pengujian didapatkan data sebagai berikut :

Tabel 2. Hasil Pengujian Motor Servo

\begin{tabular}{|c|c|c|}
\hline Pulse on & PORTD.2 & Motor Servo \\
\hline $1 \mathrm{~ms}$ to $2 \mathrm{~ms}$ & 1 & Down \\
\hline $2 \mathrm{~ms}$ to $1 \mathrm{~ms}$ & 0 & Up \\
\hline
\end{tabular}




\section{KESIMPULAN}

Didalam alat ini terdapat 2 (dua) motor stepper sebagai penggerak sumbu $\mathrm{x}$ dan $\mathrm{y}, 1$ (satu) motor servo untuk penggerak pena, 1 (satu) Shield L293D sebagai driver motor dan dikendalikan Arduino Uno R3. Secara keseluruhan, rancang bangun alat prototipe Mesin CNC 2D Berbasis Arduino Uno ini dapat bekerja dan berfungsi sebagaimana yang direncanakan, yaitu mencetak gambar atau menulis sesuai yang dikehendaki menggunakan pena secara otomatis. Hasil akurasi pencetakan gambar bergantung pada mekanisme mesin tersebut, rata rata untuk sumbu $X=89,5 \%$, sumbu $Y=89 \%$, dan sumbu $Z=98 \%$.

\section{DAFTAR PUSTAKA}

[1] Latif, 2016. Kendali Pergerakan Motor Stepper Sumbu X-Y Pada Prototipe Mesin Cutter Untuk Membuat Pola Garis Tegak Lurus Dan Persegi. Universitas Muria Kudus.

[2] Mahardika, 2014. Perancangan Mekanika Alat CNC Router Berbasis Arduino Uno. Universitas Telkom.

[3] Motor DC L293D. http://elektronika-dasar.web.id/driver-motor-dc-1293d/, di akses tanggal: 25 Oktober 2017.

[4] Motor Servo. http://elektronika-dasar.web.id/motor-servo/, di akses tanggal: 25 Oktober 2017.

[5] Motor Stepper. http://www.partner3d.com/motor-stepper-pengertian-cara-kerja-dan-jenisjenisnya/, di akses pada tanggal : 26 Oktober 2017.

[6] Purwanto, T. Pudji. 2011. Desain dan Implementasi Sistem Kendali CNC Router. Jakarta: LIPI.

[7] Setiawan, Afrie. 2011. 20 Aplikasi Mikrokontroler ATMega 8535 \& ATMega 16 Menggunakan Bascom-AVR. Andi. Yogyakarta.

[8] Silalahi, Ulber. 2006. Metodologi Penelitian. Bandung: Unpar Press.

[9] Software Inkscape. http://manual-inkscape.co.id/2013/08/tutorial-menggunakaninkscape.html, di akses pada tanggal: 26 Oktober 2017.

[10] Software Processing. https://blogs.itb.ac.id/wnugroho/processing/, di akses pada tanggal: 26 Oktober 2017.

[11] Sugiyono.2012. Metode Penelitian Kuantitatif Kualitatif dan R\&B. Bandung: Alfabeta.

[12] Sulaiman, Arif. 2012. Arduino : Mikrokontroler bagi Pemula hingga Mahir. http://buletin.balaielektronika.com, di akses tanggal: 25 Oktober 2017.

[13] Syahwil, Muhammad. 2013. Panduan Mudah Simulasi dan Praktik Mikrokontroler Arduino. Yogyakarta: Andi Publisher.

[14] Syaripudin, Amir. 2010. Elektonika 2. Jakarta: Yudhistira.

[15] Yunus, 2015. Mesin Pengebor Printed Circuit Board (PCB) Otomatis. Universitas Hasanuddin Makasar.

GO INFOTECH: JURNAL ILMIAH STMIK AUB Vol. 25, No. 1, Juni 2019 : 43 - 52 